\title{
Semantic Preference, Prosody and Distribution of Synonymous Adjectives in COCA
}

\author{
Linas Selmistraitis \\ selmistraitis@mruni.eu \\ Mykolas Romeris University, Lithuania
}

\begin{abstract}
Synonymous word pairs often become an obstacle on the road to favourable result in composing academic texts because semantic prosody and semantic preference of these words are neglected. The current study examined the concordance lines with synonymous adjectives succinct \& concise, coherent \& cohesive, precise \& accurate in the academic texts of Corpus of Contemporary American English (COCA) and identified semantics of co-occurring collocates, interchangeability of synonyms and their distribution across nine academic disciplines. The research describes the semantic arrangement of collocations with synonymous pairs of words and encourages persons with academic pursuits rely on corpus data based tools to improve knowledge of semantic prosody and preference of words with similar meanings. The study showed that near synonyms succinct \& concise, coherent \& cohesive, precise \& accurate have different semantic preference and distribution across registers which should be taken into consideration while building collocations with these words. However, semantic prosody tendencies of these synonyms are similar. The analysed synonyms cannot be used interchangeably in all contexts. They are also unevenly scattered across registers. The current study will help to improve learning, teaching, and research of English academic vocabulary in its many contexts.
\end{abstract}

Keywords: Semantic Preference; Semantic Prosody; Collocates; Synonymous Words; COCA

\section{INTRODUCTION}

As far as researchers are under constant pressure to read and publish academic texts of considerable size, research in semantic prosody and semantic preference becomes of crucial importance. Predominantly the medium of academic texts is the English language. The choice of English academic words and collocations proper for the very specific linguistic environment usually does not cause a great difficulty for native speakers. However, it is not a case for nonnative ones. Non-native speakers, students, secondary or tertiary level teachers, scientists often struggle with the choice of the correct word suitable for texts written in different academic fields. Synonymous word pairs often are a stumbling block on the road to favourable result in composing academic texts because semantic prosody and semantic preference of these words are neglected.

The research describes the semantic arrangement of collocations with synonymous pairs of words and encourages persons with academic pursuits rely on corpus data based tools to improve knowledge of semantic prosody and preference of words with similar meanings.

In the context of collocation learning, near-synonyms particularly pose a difficulty for most foreign language learners due to their similar denotational meanings but uninterchangeable semantic prosody (Hu, 2015, p. 117). Semantic prosody has an essential role in selecting correct equivalents, especially in case of near-synonyms when synonyms have identical or similar denotational meaning but usually differ in their collocational behaviours and semantic prosodies (Zhang, 2010). 
Recent research into semantic prosody and semantic preference is not extensive and the range of its practical application in academic studies and academic work is rather narrow. Besides, there are only some research works on semantic prosody and semantic preference in which target items are singled out from the Academic Vocabulary List (AVL) (Gardner \& Davies, 2014). Studies on academic vocabulary cover its various aspects but leave aside semantic prosody and semantic preference.

The study carried out by Pecoraria, Shaw, Malmströmc (2019) focus on materials for testing academic vocabulary and the approaches used to assess the validity and equivalence of the two forms of the test of academic vocabulary. Green's study describes the subset of academic vocabulary associated with particular grammatical patterns (Green, 2019). Crosson, McKeown and Ward focus on a vocabulary assessment that gauges students' depth of knowledge of academic words (Crosson, McKeown \&Ward, 2019).

Wang in his study points out that "Corpus-based studies on semantic prosody of synonyms provide a new lens to teaching and learning synonyms in English. However, using corpus-based approach to facilitate teaching and learning English synonyms is still in its infancy [...]" (Wang, 2019, 1). Research into semantic prosody and preference of the academic vocabulary is not consistent. The research is defragmented inasmuch only single items from Academic Word List are analysed with reference to the corpus (Hu, 2015; Li, 2019). A number of researchers focused on single items (words) of non-academic vocabulary (Nugroho, 2018; Wang \& Zou, 2019; Bi, 2019).

To fill this gap and complement to the studies on the importance of semantic preference and prosody in building collocations the current research focuses on semantic preference, semantic prosody and frequentative distribution across registers of synonymous pairs concise $\&$ succinct, coherent \& cohesive, precise \& accurate and examines the concordance lines with these synonyms in the academic texts from COCA. The selection of these pairs is predetermined by the fact that the words concise, succinct, coherent, cohesive, precise, accurate are included in AVL because they are a part of academic vocabulary. In COCA, they are shown with a highest frequency of their occurrence, meaning that they are highly used by the English language users and learners of English as a foreign language (EFL). The choice of these words is also predetermined by their complex functional and syntactic usage patterns and neglected co-occurrence peculiarities in building collocations. These words are also used in a vocabulary section of EFL textbooks as words which are confused by learners when characterising language and speech. The chosen words can serve as samples for investigation of other synonymic pairs to show that corpus-assisted approach is more effective, objective and reliable in distinguishing synonyms and a number of implications can be concluded in English language teaching, learning, testing and research.

The aim of the research is to identify the differences and similarities in semantic prosody, preference and distribution of collocates of concise \& succinct, coherent \& cohesive, precise \& accurate across different academic fields in COCA and to identify possibility of interchangeable use of synonyms within each synonymic pair as an illustration of the importance of semantic prosody and preference in academic writing.

To achieve the aim of the research the following objectives are set:

1) To extract concordance lines with collocates of concise \& succinct, coherent \& cohesive, precise \& accurate from Corpus of Contemporary American English and examine them;

2) To identify the most frequent collocates (raw and relative frequencies) of each synonym in the pairs of synonyms under analysis and delineate semantic characteristics of these collocates;

3) To describe semantic prosody and preference of collocates; 
4) To identify raw frequencies of distribution of synonymous pairs across different academic disciplines.

The research approaches employed in the current study are qualitative and quantitative. From the qualitative perspective the node words concise \& succinct, coherent \& cohesive, precise \& accurate and their collocates were subjected to the analysis using descriptive method and the KWIC (Keyword in Context) method through the concordance lines. Quantitative approach was realised through identification of raw and relative frequency of collocates of the node words and their distribution raw frequency across academic fields using quantification instrument provided by COCA.

\section{SEMANTIC PROSODY AND SEMANTIC PREFERENCE}

Semantic prosody has been in the focus of researchers in the course of the recent three decades. Notwithstanding that the notion of semantic prosody remains "a problematic concept, mainly because it has been used to speak of such different things as connotation, evaluation, appraisal, pragmatic force, irony and insincerity, all of which are kinds of secondary meaning, and none of which is the same as the others" (Philip, 2011, p. 58). The problematic character of semantic prosody first of all lies in different approaches to semantic prosody itself adapted in the literature. The second reason is the absence of clear cut division between semantic prosody and lexical environment. Semantic prosody is inescapably dependent on habitual lexical environment. However, such a link with lexical environment is not unique only for semantic prosody. As an example of such interdependence could be relationship between connotations of the words and lexical environment. Still, connotation of the word can be collocational and non-collocational while semantic prosody can only be collocational.

The originators of semantic prosody are considered to be Sinclair (1991) and Louw (1993). Louw, a close associate of Sinclair, publicly coined the term "semantic prosody" in his 1993 work which remains the most often cited source when dealing with issues of semantic prosody. Firth's theory related to prosody in phonological terms lead to the coinage of the term "semantic prosody". In phonology prosody refers to the phenomenon when preceding and following sounds define the realization of a particular phoneme. Stubbs gave his own point of view towards Sinclair's concept of semantic prosody and called it as 'discourse prosody' acknowledging semantic relations between node and collocates. Stubbs distinguished three categories - positive, negative and neutral - into which discourse prosody can fall (Stubbs, 2002, p. 225).

Ideas of semantic prosody further have been developed by 'semantic preference', which is closely related to semantic prosody and "refers to the semantic categories shared by the frequent collocates of a specific node item" (Partington, 2004). One obvious difference between semantic prosody and semantic preference is that "semantic preference may be in favour of any definable semantic field, but semantic prosody is always either for positive or for negative evaluation" (McEnery \& Hardie, 2011, p. 137). Positive prosody expresses the speaker's approval and negative prosody expresses the speakers' disapproval. In other words, semantic prosody defines how the utterance has to be interpreted functionally in the text. However, these two phenomena, i.e. semantic preference and semantic prosody, are either used as the same phenomenon or they are interpreted as different but closely related.

Hoey considers semantic prosody as embracing two different concepts and chooses to split semantic prosody into "semantic associations" for the connotative and evaluative meanings, and "pragmatic associations" for the discourse function (Hoey, 2005). Hunston (2007) interprets semantic prosody as it is restricted by Sinclair referring to it as the discourse function of a unit of meaning, and suggests that the term 'semantic preference' has to "refer to 
the frequent co-occurrence of a lexical item with items expressing a particular evaluative meaning" (Hunston, 2007, p. 266). Begagić draws a dividing line between these terms stating that "semantic preference can be defined as the relation between a word form and set of semantically related words, whereas the concept of semantic prosody of a given word or phrase occurs in the context of that particular lexical item with other words or phrases" (Begagić, 2013, p. 403).

The scope of semantic preference and semantic prosody is different. Preference is realised at the level of semantic set while semantic prosody affects wider stretches of text. Semantic preference is affected by collocates of the node contrary to semantic prosody which is the feature of the node word. According to Partington, semantic prosody dictates the general environment which constrains the preferential choices of the node item, and "semantic preference contributes powerfully to building semantic prosody" (Partington, 2004, p. 151). According to Essimaje (2014), semantic preference restricts regular co-occurrence to items that share a semantic feature. It implies the identification of similarity of meaning across word boundaries. Thus, semantic preference is the likelihood that words that share meaning domains will co-occur.

Philip (2009) proposes that Hoey's term 'semantic association' should be introduced as an intermediate stage between semantic preference and semantic prosody. According to Philip, this additional category covers "connotative, expressive and evaluative meanings associated with lexical items" (Philip, 2011, p. 61). It allows 'semantic prosody' to be used for the discourse function and to keep with the idea that "semantics [...] deals with meaning, and prosody [...] typically ranges over combinations of words in an utterance rather than being attached just to one" (Sinclair, 2003, p. 17).

Semantic prosody and semantic preference is closely related to collocations. Collocation is most commonly associated with the name of J. R. Firth. Collocations are based on mutual expectancy of the collocates and on their co-occurrence frequencies. The meaning that words convey in text is a product of collocation, which is different from meaning in the mind. As Philip puts it, "collocations can be viewed as co-creating meaning (in Firth) or as modifying meaning (in the Russian tradition). [...] Collocation may also sharpen the focus of the constituents meaning" (Philip, 2011, p. 42), as in the case of the collocate dark night when the word dark reinforces the element of darkness which is already in the word night.

Corpus linguistics gave theoretical grounds and instrument of an exhaustive research of semantic prosody and semantic preference through investigation of collocations in different corpora with the help of computer software. Philip also advocated the importance of corpus linguistics because "collocation lies at the heart of corpus query software applications and the analysis of concordances" (Philip, 2011, p. 43). As Begagić puts it, "There are almost no works on semantic preference and semantic prosody outside the scope of corpus linguistics, as empirical data used from corpora enable the linguist to make statements that are objective and based on natural language" (Begagić, 2013, p. 403).

In corpus linguistics collocates are those pairings of words that occur recurrently in the corpus and semantic prosody. The most significant merit of the usage of computer software to the study of collocations are quantification and retrievability because corpus query software can extract all instances of a node and with all its attested co-texts. Co-occurrence need not be contiguous nor need its sequencing be fixed, but "the collocates are expected to occur within five words left or right of each other, and the closer they are, the more significant their relationship" (Sinclair \& Teubert, 2004 as cited in Philip, 2011, p. 43)

Semantic prosody determines the meaning of the whole lexical item, expressing its function and showing how the remaining part of the item has to be interpreted. The choice of the wrong word might lie in neglecting semantic prosody features of the word. Studies of semantic prosody are deeply tied to the phenomenon of collocational sequence of words that 
often are found together in a particular semantic environment where words collocate could be positive, neutral or negative (Elahi \& Rahbar, 2018).

A number of studies emerged from the perspective of using semantic preference or semantic prosody as the framework of analysis. Li (2019) drew upon Sinclair's model of extended lexical units and employed a corpus-assisted approach to the study of synonyms preserve and conserve, summarising the semantic preference and semantic prosody by examining the collocations with these words. A Corpus-based contrastive study on semantic prosody of English near synonyms motive and motivation was conducted by Wang (2019). Nugroho (2018) used the framework of semantic prosody and preference studying two nearsynonymous words rich and wealthy. Hu (2015) carried out the research on semantic prosody of three adjective synonymous pairs initial/preliminary, following/subsequent, and sufficient/adequate.

\section{ACADEMIC VOCABULARY LIST}

The analysis of collocations presupposes the awareness of differences in collocations with near synonyms. As far as the current research focuses on semantic prosody and semantic preference of near synonyms in AVL, the current literature review also zeroes in on AVL history.

Going back to the $20^{\text {th }}$ century $7^{\text {th }}$ or $8^{\text {th }}$ decades when corpus linguistics was at its initial phase and computing power was weak, academic word lists were compiled manually by scholars who based their lists on academic materials such as textbooks, research articles, etc. In 1984, one of the most popular academic word lists was compiled by Xue and Nation (Xue \& Nation, 1984), which was in use for more than 15 years. A new academic word list was produced by Coxhead in 1998 based on wider application of corpora and it was in use for a decade as one of the flagship in the field (Coxhead, 2011).

Gardner and Davies new Academic Vocabulary List (AVL) is derived from a 120million-word academic subcorpus of the 425-million-word Corpus of Contemporary American English. AVL makes a difference between academic texts and other materials. The list covers approximately $14 \%$ of academic texts in both COCA (120 million+ words) and the British National Corpus (33 million+ words). The list comprises nine scientific disciplines: 1) education, 2) humanities, 3) history, 4) social science, 5) philosophy, religion, psychology, 6) law and political science, 7) science and technology, 8) business and finance, 9) medicine and health. Originally, about three quarters of words come from academic journals. Later Gardner and Davies "decided to 'soften' the journal-heavy corpus by adding 31.5 million words from academically oriented magazines for all disciplines except Humanities and Education, where there are few topic-specific magazines" (Gardner \& Davies, 2014).

According to Gardner and Davies, "Almost without exception, experts are calling for more explicit instruction of academic vocabulary, including more focused lists of 'core' academic vocabulary", as well as lists specific to certain disciplines of education (e.g. philosophy, political science, history, philosophy) (Gardner \& Davies, 2014).

The studies in academic word list have developed in recent years. However, they were not related to insights into AVL semantic prosody and preference. Researchers concentrated on creating discipline-specific academic vocabulary lists. In 2016 a new medical academic word list was created (Lei, Liu, 2016). An attempt for creating English for Academic Purposes Word List (EAPWL) was made in 2017 (Khani, Saeedi, 2017). A number of research articles were dedicated to the use of academic word list in educational process. McDonough, Neumann and Hubert-Smith carried out study on how accurately EAP students use academic words (McDonough, Neumann \& Hubert-Smith, 2018). Others explored extent to which teachers used the Academic Vocabulary List working with their learners (Banister, 2016) or its use in doctoral thesis (Pathan, Memon, Memon, Shah, Magsi, 2018). 


\section{METHODOLOGY: DATA AND DATA ANALYSIS}

The scope of the research is limited to three synonymous adjectival pairs: concise \& succinct, coherent \& cohesive, precise \& accurate. The synonyms are taken from AVL (Gardner \& Davies, 2014). It is the most current, comprehensive, precise list of core academic vocabulary in existence today and it is useful in completing a great number of academic tasks: analysing the level of text difficulty and richness, assessing the student's vocabulary knowledge and growth, determining the vocabulary components of academic curricula. AVL contains the standard high-frequency function words found in almost all other academic vocabulary lists.

In the research, the corpus tool employed to identify the most frequent synonyms of the key words was Sketch Engine. It is a corpus tool used by researchers and language teachers which allows the user to view word sketches. One of Sketch Engine core functions is Thesaurus enabling the researcher to identify the similarity of the chosen words and frequency of synonyms. Frequency here refers to the number of occurrences or hits. It is an absolute figure, and it is not calculated using a specific formula. Table 1 indicates the most frequent synonyms in synonymic groups.

TABLE 1 . Frequencies of synonyms concise \& succinct, coherent \& cohesive, precise \& accurate

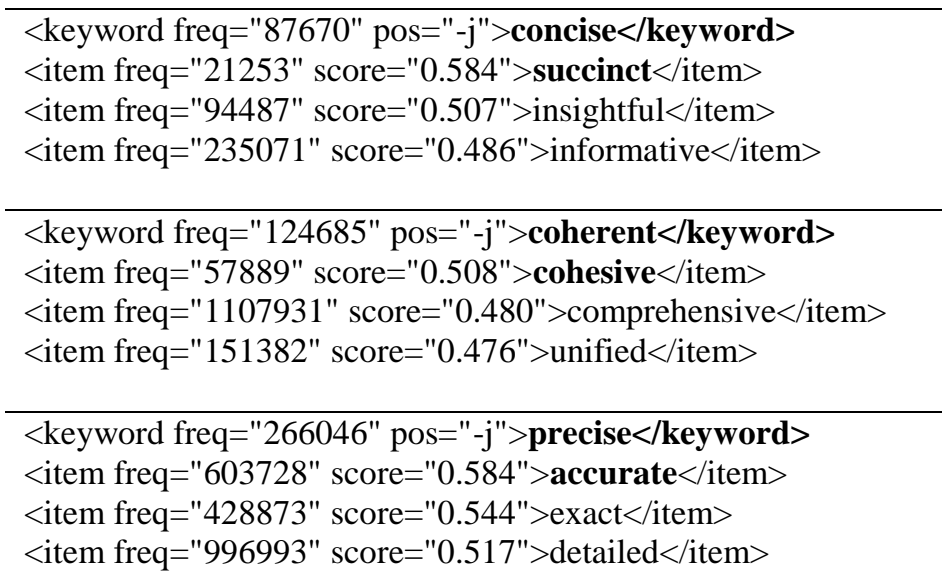

2000 concordance lines in COCA were selected for the analysis to define semantic prosody and semantic preference of the synonyms: concise \& succinct, coherent \& cohesive, precise \& accurate: 100 concordance lines with most frequent 20 collocates of each synonym. Distinction between lemmas is not taken into consideration.

Behaviour of adjectival pairs was examined with reference to one of the largest freely available genre-balanced COCA developed by Davies. COCA offers unparalleled insight into variation in English. It is often compared with British National Corpus (BNC). The latter is 5 times smaller because it does not tend to provide lower-frequency constructions which are available in COCA. The BNC has a much wider range of spoken sub-genres, while COCA includes unscripted conversation on TV and radio shows. COCA contains more than 560 million words of text (20 million words each year 1990-2017) and it is equally divided between five registers: academic, fiction, spoken, magazines and newspapers journals. Besides, it gives distribution of the words inside academic register according to 9 academic fields such as history, education, sociology, law, humanities, philosophy, sciences, business, medicine. The corpus is continuously increasing. In 2020, COCA will be expanded with the three new genres which will be blogs, other web pages, and TV and movie subtitles. COCA suits well the aim of the current research as far as it allows the researcher to define crucial differences in 
realisation of semantic preference and semantic prosody of particular lexical items in different registers.

Following Hu's methodology ( $\mathrm{Hu}, 2015)$, the current study examined the concordance lines with synonymous adjectives in the academic texts from COCA and identified semantics of co-occurring collocates, interchangeability of synonyms and their distribution across different academic disciplines.

The research takes into consideration the following data about the word: definitions, relative frequency across different academic disciplines, the top collocates of the word, which provide useful insights into meaning, usage, and possibilities of collocations.

The AVL list was screened to find out whether the chosen synonyms are included in the core academic vocabulary. The meanings of concise \& succinct, coherent \& cohesive, precise $\&$ accurate were checked against $9^{\text {th }}$ edition of Oxford Advanced Learner's Dictionary (OALD, 2015) to identify whether the words share denotative components and can be ascribed to near synonyms.

All selected words belong to the same part of speech and do not have homonyms of other parts of speech.

The analysis of the synonymous pairs is arranged in the following way:

1) semantic preference of collocates is described;

2) semantic prosody is identified;

3) distribution across 9 academic fields is presented.

Hu's methodology proved that to obtain reliable results 20 most frequent collocates within a span of 4 words to both the left and right in a concordance lines have to be taken (Hu, 2015 , p. 120). The collocates of the synonyms under analysis and the number of their occurrences beginning with the most frequent one are presented in Tables 2-4. In Tables 2-4 collocates which are the same for both paired synonyms are marked in bold.

After defining semantic prosody and semantic preference, distribution of synonyms across different academic fields was analysed: history (HIS), education (EDU), sociology (SOC), law (LAW), humanities (HUM), philosophy (PHIL), sciences (SCI), medicine (MED) business (BUS). Distribution of the synonyms across different academic fields is presented in Figures 1-3.

\section{RESULTS AND DISCUSSION}

The research of the synonymous word concise \& succinct, coherent \& cohesive, accurate \& precise yielded the following results.

\section{CONCISE \& SUCCINCT}

Table 2 presents 20 most frequent collocates co-occurring with the synonyms concise \& succinct in COCA. Almost half of them coincide. Both synonyms collocate with the words clear, statement, overview, summary, description, provide, definition, account. However, their frequency is different.

In general, concise is twice more frequently used than the word succinct: correspondingly 347 and 174 co-occurrences in academic register. The most frequent collocate co-occurring with succinct is another adjective, i.e. clear: 75 occurrences (22\% - relative frequency) of all cases. However, in terms of parts of speech the majority of 20 most frequent collocates of concise \& succinct are nouns: concise goes with 13 nouns, and succinct has 14 noun collocates. Adjectival collocates are not frequent: concise goes with five adjectives, and succinct has two 
adjectives. Two verbal collocates go with concise, and four cases of verbal collocates are found with succinct.

TABLE 2. Number of occurrences of 20 most frequent collocates with synonyms concise / succinct in COCA

\begin{tabular}{ccccc}
\hline \multicolumn{2}{c}{ CONCISE } & \multicolumn{2}{c}{ SUCCINCT } \\
\hline No. & Collocate & $\begin{array}{c}\text { Number of } \\
\text { occurrences (relative } \\
\text { frequency of 20 most } \\
\text { frequent collocates) }\end{array}$ & Collocate & $\begin{array}{c}\text { Number of occurrences } \\
\text { (relative frequency of 20 } \\
\text { most frequent collocates) }\end{array}$ \\
\hline 1. & CLEAR & $75(22 \%)$ & STATEMENT & $13(8 \%)$ \\
2. & HISTORY & $23(7 \%)$ & SUMMARY & $12(7 \%)$ \\
3. & STATEMENT & $20(6 \%)$ & DESCRIPTION & $11(6 \%)$ \\
4. & MANNER & $17(5 \%)$ & EXPLANATION & $9(5 \%)$ \\
5. & OVERVIEW & $13(4 \%)$ & PROVIDES & $9(5 \%)$ \\
6. & SUMMARY & $13(4 \%)$ & OFFERS & $7(4 \%)$ \\
7. & DESCRIPTION & $13(4 \%)$ & GAVE & $7(4 \%)$ \\
8. & PROVIDES & $13(4 \%)$ & CLEAR & $7(4 \%)$ \\
9. & DEFINITION & $10(3 \%)$ & ACCOUNT & $6(3 \%)$ \\
10. & ACCURATE & $9(3 \%)$ & OVERVIEW & $5(3 \%)$ \\
11. & DESCRIPTIONS & $8(2 \%)$ & ANSWER & $5(3 \%)$ \\
12. & ACCOUNT & $8(2 \%)$ & LETTER & $4(2 \%)$ \\
13. & SHORT & $8(2 \%)$ & DEFINITION & $4(2 \%)$ \\
14. & ENCYCLOPEDIA & $7(2 \%)$ & PROVIDED & $4(2 \%)$ \\
15. & DICTIONARY & $7(2 \%)$ & READABLE & $3(2 \%)$ \\
16. & COMPREHENSIVE & $7(2 \%)$ & PHRASE & $3(2 \%)$ \\
17. & SIMPLE & $7(2 \%)$ & FASHION & $3(2 \%)$ \\
18. & FORMAT & $6(2 \%)$ & PRESENTATION & $3(2 \%)$ \\
19. & GUIDE & $6(2 \%)$ & ACCOUNTS & $3(2 \%)$ \\
20. & OFFERS & $6(2 \%)$ & STATEMENTS & $3(2 \%)$ \\
& TOTAL ALL & $\mathbf{3 4 7}$ & TOTAL & $\mathbf{1 7 4}$ \\
\hline
\end{tabular}

Speaking about semantic preference, which restricts regular co-occurrence to items that share a semantic feature, the nouns which collocate with concise \& succinct often denote a definite or clear expression, review or account of the situation in speech or writing.

The word concise also collocates with the types of books such as dictionary and encyclopaedia while the synonym succinct does not have such collocations. For example:

(1) In 1932 the Rockefeller Foundation and in 1935 the International African Institute sponsored Hans Melzian's A Concise Dictionary of the Bini Language (1937), [...].

(2) These definitions are based on information in Randel, Don Michael, ed., The Harvard Concise Dictionary of Music and Musicians.

(3) According to Merriam Webster's Concise Encyclopedia, dance is a "form of expression that uses bodily movements that are rhythmic, patterned (or sometimes improvised), and usually accompanied by music.

The meanings of the verbs that collocate with concise/succinct have a marker (common seme) 'to provide', and the meanings of the adjectives which go with concise/succinct possess common component of meaning 'easily understood' and 'correct'. For example:

(4) By avoiding jargon, the dictionary offers concise and easily accessible information for users.

(5) Criminal Law Essentials provides up-to-date, comprehensive and concise coverage of criminal law in Scotland. 
The majority of the twenty collocates of the synonyms concise \& succinct are associated with any polarized semantic prosody, neither positive nor negative. If the collocates of the node words have neutral semantics in concordance lines they create neutral prosody. Neutral collocates are words not expressing emotions, unbiased, not denoting approval or disapproval. They do not have any emotional connotations that could relate them to negatively or positively charged words. Words having positive semantics are directly related to qualities or features that are good or useful. Negative semantics is associated with harmful, unpleasant or not wanted effects, consequences, things denoting collocates.

In the following collocations, collocates of the synonyms concise \& succinct have neutral prosody. The collocates statement, description, overview, summary do not have any emotional connotations that could relate them to negatively or positively charged words. For example:

(6) Perhaps the most succinct statement of Ruscha's project comes from a line in Shakespeare's Hamlet he has depicted multiple times: "Words without thoughts never to heaven go."

(7) Hirons provides a succinct description of the three conventions that have been used historically for cataloging serials.

(8) The present paper provides a concise overview of the " workaholism syndrome."

(9) Table 1 provides a concise summary of the appropriate applications for the various types of thermal insulation.

The adjectives which have positive denotative meaning added before other words strengthen positive evaluation of the topic. The following adjectival collocates reinforce positive semantic prosody of the node word concise: clear, accurate, comprehensive, simple, short. For example:

(10) It was the simple and concise structure of scripts, where operations are applied to whole maps without explicitly iterating over the cells, that made map algebra a popular language.

(11) However, a straightforward, short, concise feedback form handed in at the end of each class session is appropriate and helpful in determining student reaction.

The word succinct has fewer collocates with positive prosody: clear, readable. For example:

(12) For such readers, the book is readable and succinct in comprehensively examining sociopolitical issues in contemporary Mexico.

The synonyms concise \& succinct often go together with the collocate clear which manifests positive semantic prosody. Semantics of the very word clear in a language as a system bears positive evaluation of a characterised phenomenon. The collocate clear is the most frequent (75 occurrences) with the word concise. For example:

(13) By week 15, students were fairly comfortable explaining their ideas and business models in clear and concise terms.

(14) [...] this Article focuses on this work because it is a clear and succinct statement of the Sources Thesis.

Figure 1 shows distribution of the words concise \& succinct across different academic fields. It illustrates how differently in frequentative aspect two synonyms are used depending which field they function in. 


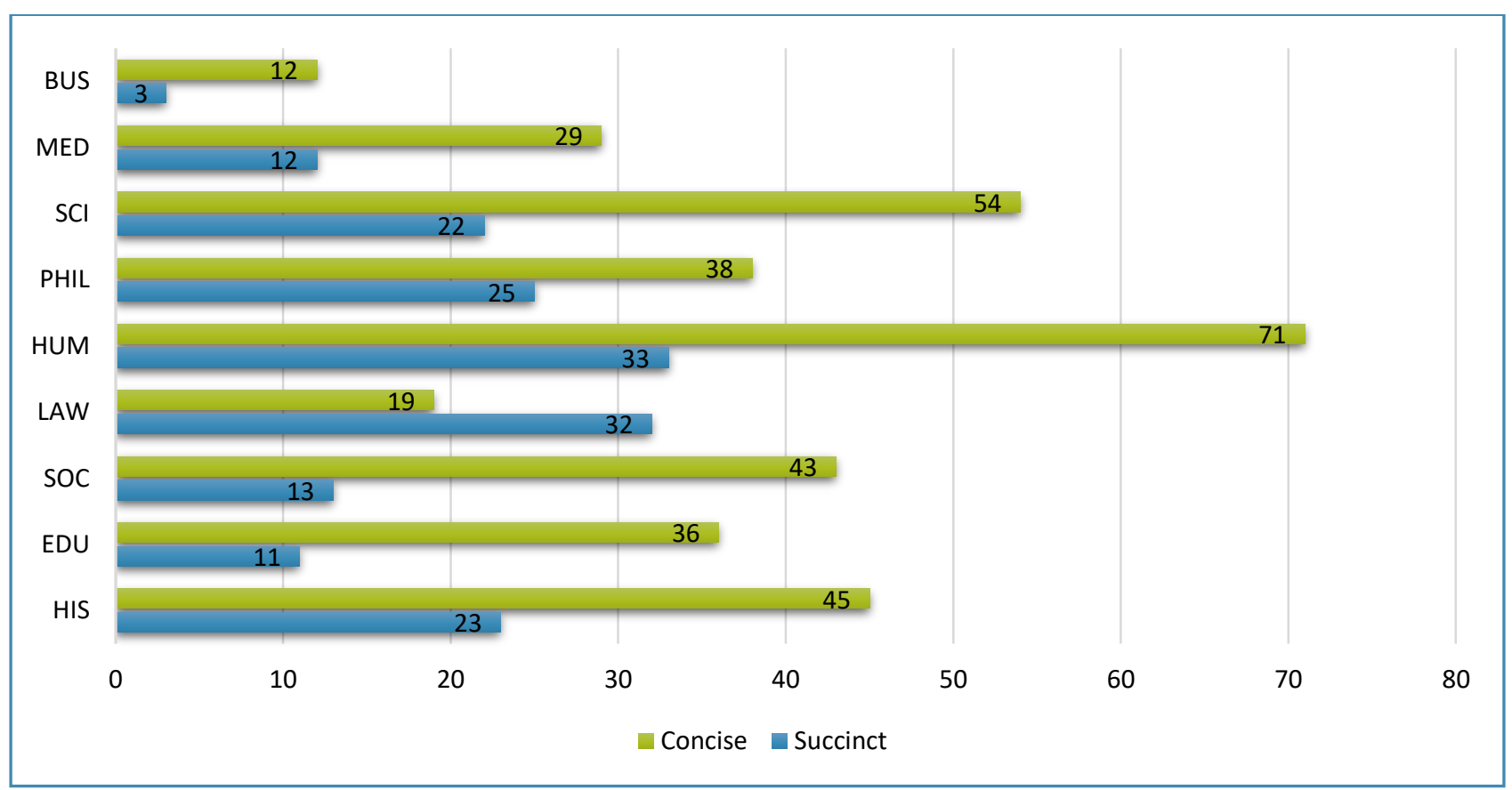

FIGURE 1. Distribution of concise \& succinct across academic fields

It can be noticed that concise \& succinct are more frequent in humanities, which can be explained by the fact that these words often collocate with the words denoting written or spoken types of texts: chapter, notice, answer, telling, prose, instruction, text, statement. Least frequent usage is noticed in academic fields of business and medicine. The biggest difference in usage of concise \& succinct is in education texts: correspondingly 36 and 11 occurrences.

\section{COHERENT/COHESIVE}

Both synonyms characterise something united as whole. The synonyms coherent \& cohesive have only three common collocates: whole, narrative, identity. Although denotative meaning of both synonyms refers to the quality of being united, logically arranged as a whole they usually collocate with different words.

TABLE 3. Number of occurrences of 20 most frequent collocates with synonyms coherent \& cohesive in COCA.

\begin{tabular}{ccccc}
\hline \multicolumn{2}{c}{ COHERENT } & \multicolumn{2}{c}{ COHESIVE } \\
\hline No. & Collocate & $\begin{array}{c}\text { Number of occurrences } \\
\text { (relative frequency of } \\
\text { 20 most frequent } \\
\text { collocates) }\end{array}$ & Collocate & $\begin{array}{c}\text { Number of occurrences } \\
\text { (relative frequency of 20 } \\
\text { most frequent collocates) }\end{array}$ \\
\hline 1. & POLICY & $66(3 \%)$ & GROUP & $66(11 \%)$ \\
2. & WHOLE & $62(3 \%)$ & UNIT & $62(11 \%)$ \\
3. & STRATEGY & $53(3 \%)$ & TEAM & $57(10 \%)$ \\
4. & FRAMEWORK & $43(2 \%)$ & COMMUNITY & $45(8 \%)$ \\
5. & THEORY & $42(2 \%)$ & FORCE & $43(8 \%)$ \\
6. & CLEAR & $39(2 \%)$ & WHOLE & $43(8 \%)$ \\
7. & CONSISTENT & $36(2 \%)$ & GROUPS & $38(7 \%)$ \\
8. & VISION & $34(2 \%)$ & TOGEATE & $37(7 \%)$ \\
9. & LACK & $34(2 \%)$ & FORM & $32(6 \%)$ \\
10. & NARRATIVE & $32(2 \%)$ & NARRATIVE & $30(6 \%)$ \\
11. & IDENTITY & $31(2 \%)$ & SOCIETY & $25(4 \%)$ \\
12. & CREATE & $30(2 \%)$ & & $22(4 \%)$ \\
\hline
\end{tabular}




\begin{tabular}{rcccc}
\hline 13. & SINGLE & $28(1 \%)$ & POLICY & $22(4 \%)$ \\
14. & INTEGRATED & $26(1 \%)$ & STRONG & $20(3 \%)$ \\
15. & PRODUCE & $21(1 \%)$ & IDENTITY & $16(3 \%)$ \\
16. & UNIFIED & $18(1 \%)$ & COHERENT & $15(3 \%)$ \\
17. & CONSTRUCT & $17(1 \%)$ & UNITS & $15(3 \%)$ \\
18. & THEORETICAL & $17(1 \%)$ & RELATIVELY & $15(3 \%)$ \\
19. & PICTURE & $17(1 \%)$ & BUILD & $15(3 \%)$ \\
20. & QUANTUM & $16(1 \%)$ & TIES & $14(2 \%)$ \\
& TOTAL & $\mathbf{1 9 1 9}$ & TOTAL & $\mathbf{5 8 9}$ \\
\hline
\end{tabular}

The word cohesive most frequently collocates with collective nouns denoting a number of people: group, unit, team, community, society. Collocations with these words make up a half $(51 \%)$ of most frequent cases. While the synonym coherent usually goes together with the words denoting a plan of actions for particular purpose, a set of ideas or description: policy, strategy, framework, theory, vision, picture. They make $13 \%$ of all collocates in academic register. For example:

(15) Einstein never achieved his goal of a unified theory to explain the natural world in a single, coherent framework.

(16) The only way to avoid getting sucked into a costly fight over electronic records is to catalog them for easy retrieval and to have a regular, coherent policy for destroying documents.

(17) In this new picture, we combine these two mythologies into one coherent picture: We have a constant genesis, or boiling of universes, in an ocean of cosmic nothing or Nirvana.

(18) The application of increased military resources and a coherent strategy almost certainly will have an effect on the Afghan battlefield if given enough time to succeed and backed by a complimentary civilian strategy.

Coherent \& cohesive collocate with verbs which indicate the process of bringing something into existence. For example:

(19) Now is the perfect time to produce concise guidelines in the hope that a more succinct suite of guidance can reach a larger audience.

(20) iAbacus helps leaders create concise and high impact plans they'll be proud to publish and confidently share with others.

(21) Other technical specialists would be optimised as the ministry strives to build cohesive, sustainable communities across Guyana.

Adjectival collocates are richer in their variety with coherent (six collocates) than with cohesive (two collocates) and usually have meaning of being linked and logical, thus reinforcing positive prosody. For example:

(22) The West needs a more coherent strategy toward the Black Sea region and those countries lying further eastward around the Caspian.

(23) Having made the Afghan war the edifice of his struggle against violent extremism, President Obama has been struggling to shape a coherent strategy.

Only two collocates with the word cohesive have positive prosody: strong, coherent. For example:

(24) Stable hydrogen bonds also lead to the strong cohesive forces underlying the unusually high surface tension of water.

(25) $<\ldots>$ it's important that a foreign policy has a clear, consistent and easily coherent following and that's the hallmark of many great foreign policy.

(26) Sequencing in pretence appears to be a forerunner of the ability to think and reason in a coherent and cohesive manner.

(27) They were able to portray a fairly coherent and cohesive picture to the public and present legitimate democratic alternatives to the Spanish electorate. 
As the examples (26) and (27) illustrate, positive prosody can be strengthened by the collocation built of the very synonyms coherent \& cohesive: the word cohesive is always preceded by the word coherent.

If we speak about noun collocates, a scrutiny of the collocates of coherent \& cohesive reveals that they co-occur most frequently with terms and thus exhibit neutral prosody. Only in the case of lack of something the collocate of the word coherent has negative prosody as far as lack denotes something in shortage which has negative emotional charge. Such collocations are usually found in the sentence related to the political affairs, war, fighting or threat of terrorism. For example:

(28) The lack of countermeasures, lack of coherent policy, lack of intra-government cooperation, lack of international cooperation, make you ripe targets for terrorism.

Regarding the distribution of coherent and cohesive, coherent appears more frequently than coherent across varying academic fields.

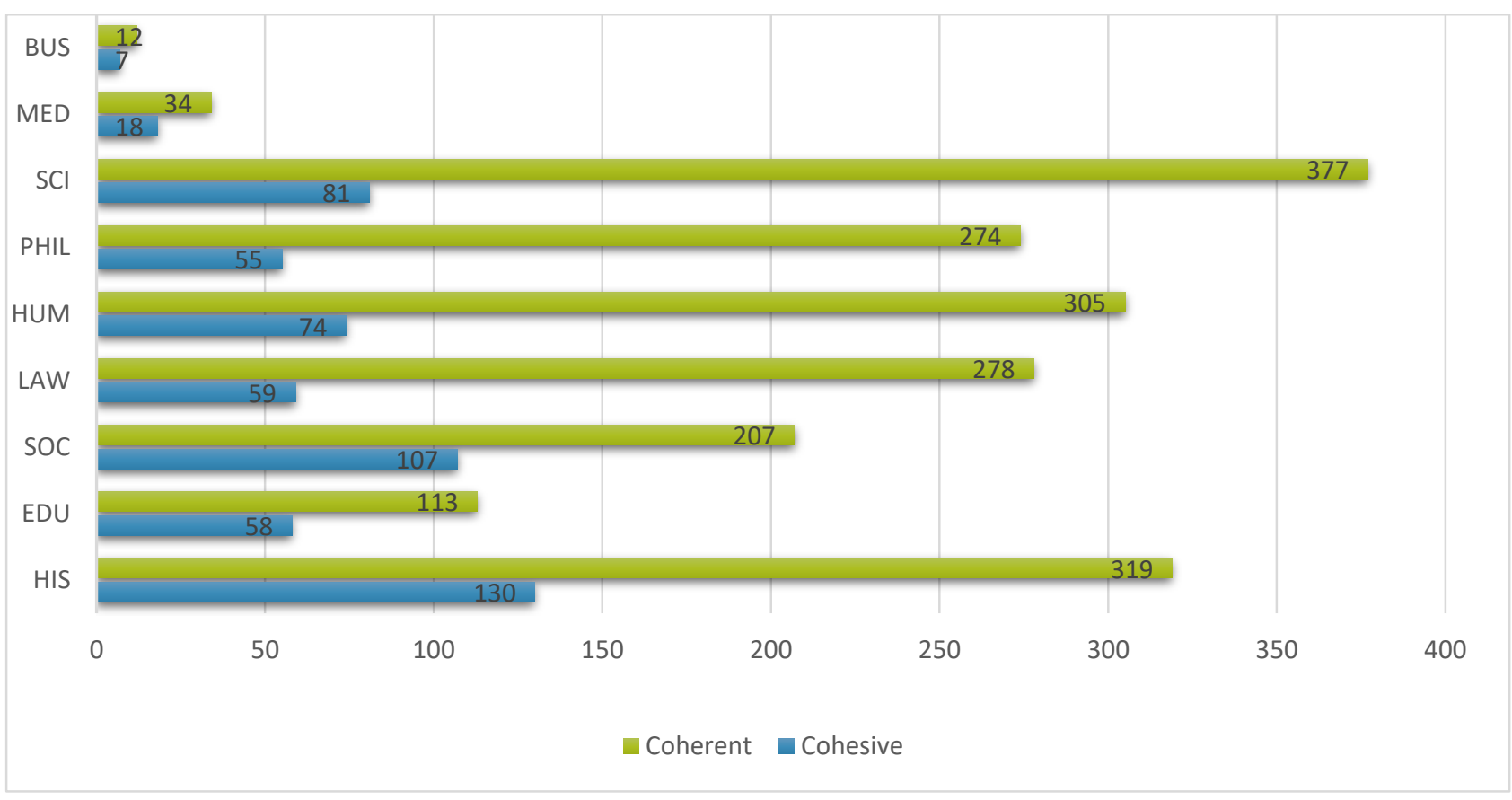

FIGURE 2. Distribution of coherent \& cohesive across academic fields

The word coherent is most common in sciences, and the word cohesive in history field. The research revealed that coherent appears to be a word that is especially frequently used in sciences, humanities, historical, philosophical and law context. However, it is rather rare in business and medical context. Similar ratio of occurrence of the word concise is noticed across these academic fields.

\section{PRECISE \& ACCURATE}

Both synonyms are associated with qualities such as clear and correct.

After the observation of the concordance lines it is obvious that three collocates are overlapping for precise \& accurate: estimates, measurement, description. 
TABLE 4. Number of occurrences of 20 most frequent collocates with synonyms precise \& accurate in COCA.

\begin{tabular}{|c|c|c|c|c|}
\hline \multirow[b]{2}{*}{ No. } & \multicolumn{2}{|c|}{ PRECISE } & \multicolumn{2}{|c|}{ ACCURATE } \\
\hline & Collocate & $\begin{array}{c}\text { Number of } \\
\text { occurrences (relative } \\
\text { frequency of } 20 \text { most } \\
\text { frequent collocates) }\end{array}$ & Collocate & $\begin{array}{c}\text { Number of occurrences } \\
\text { (relative frequency of } 20 \\
\text { most frequent } \\
\text { collocates) }\end{array}$ \\
\hline 1. & DEFINITION & $80(2 \%)$ & MORE & $1212(20 \%)$ \\
\hline 2. & NATURE & $76(2 \%)$ & INFORMATION & $443(8 \%)$ \\
\hline 3 . & MEANING & $64(2 \%)$ & PROVIDE & $211(4 \%)$ \\
\hline 4. & LOCATION & $49(1,5 \%)$ & ASSESSMENT & $148(3 \%)$ \\
\hline 5. & ESTIMATES & $48(1,5 \%)$ & DIAGNOSIS & $114(2 \%)$ \\
\hline 6. & MOMENT & $41(1 \%)$ & PICTURE & $113(2 \%)$ \\
\hline 7. & MEASUREMENT & $40(1 \%)$ & DESCRIPTION & $93(1,5 \%)$ \\
\hline 8. & DETAILS & $35(1 \%)$ & ESTIMATES & $92(1,5 \%)$ \\
\hline 9. & MEASUREMENTS & $31(1 \%)$ & RELIABLE & $90(1,5 \%)$ \\
\hline 10. & ACCURATE & $27(1 \%)$ & MEASUREMENT & $78(1 \%)$ \\
\hline 11. & TIMING & $25(1 \%)$ & COMPLETE & $78(1 \%)$ \\
\hline 12. & DATE & $24(1 \%)$ & PREDICTIONS & $75(1 \%)$ \\
\hline 13. & ALLOWS & $22(0,5 \%)$ & REPRESENTATION & $72(1 \%)$ \\
\hline 14. & CONTOURS & $21(0,5 \%)$ & OBTAIN & $65(1 \%)$ \\
\hline 15. & DEFINITIONS & $20(0,5 \%)$ & TIMELY & $61(1 \%)$ \\
\hline 16. & MECHANISMS & $20(0,5 \%)$ & IDENTIFICATION & $61(1 \%)$ \\
\hline 17. & WHATEVER & $20(0,5 \%)$ & MEASUREMENTS & $55(1 \%)$ \\
\hline 18. & DESCRIPTION & $20(0,5 \%)$ & REASONABLY & $51(1 \%)$ \\
\hline 19. & DETERMINING & $17(0,5 \%)$ & REFLECTION & $46(1 \%)$ \\
\hline \multirow[t]{2}{*}{20.} & MOVEMENTS & $16(0,5 \%)$ & EFFICIENT & $40(1 \%)$ \\
\hline & TOTAL & 3438 & TOTAL & 5885 \\
\hline
\end{tabular}

The difference between usage of precise \& accurate in COCA is also found. The word precise goes together with words related to expression of temporality and locality: moment, date, timing, location, contours. For example:

(29) Furthermore, although the precise timing of an invasion is impossible to forecast, the relative risk of invasion for various species can be estimated and prioritized from data on environmental conditions and changes in vector activity.

(30) The fourth edition of the Small Landscapes appeared at the precise moment when recent decades of positive growth and renewal intersected with the feared threat of continued violence and instability [...]

The word accurate shows preference for abstract nouns denoting proving, identification, discovering: diagnosis, reflection, identification, presentation, picture. For example:

(31) An accurate picture of the size and contours of illicit drug use is a prerequisite for informed public debate and policy making.

(32) In medical imaging, the accurate diagnosis of a disease depends on both image acquisition and image interpretation.

If we speak about verb collocates, precise frequently goes with the verb allow. Accurate collocates with the verbs provide and obtain which are antonyms. Accurate is the synonym which exhibits rare cases of occurring together with an adverb, i.e. more and reasonably. For example:

(33) The mixer truck has an onboard electronic scale that allows precise adjustments to be made to the compost mix.

(34) RT models generally require a large sample size to obtain accurate and stable item parameters.

(35) These were compared to experimental data to ensure that the calculations were reasonably accurate. 
Prosody of the synonyms precise \& accurate is mostly neutral because they usually go with collocates which do not express positive or negative emotions. However, the word accurate has more positive prosody collocates than precise, including such words as reliable, complete, timely, efficient which evaluate the topic in examples (36-39) in a positive way. For example:

(36) Regarding the quality of the documentation, the files were coded according to whether a participant's written diagnostic report included a complete battery of tests, which was defined objectively to allow for reliable and accurate coding.

(37) In turn, all of these features impact the ability to develop a 'global' method yielding accurate and reliable results.

(38) Moreover, additional funds could be used to better train IRS employees so that their responses would be more timely and accurate.

(39) The OSC was created to provide accurate and timely information to stakeholders--school board members, employees, families, business leaders, community members, and the media.

As the examples above illustrate the same collocates of the word accurate can take both postpositional and prepositional place in a concordance line.

It should be mentioned that there are cases when both synonyms precise \& accurate are used in the same sentence. Juxtaposition of both synonyms in one sentence shows that shades of meanings of these words are different. For example:

(40) Audio taped interviews captured precise and accurate verbiage while field notes were taken to obtain the implicit and explicit details of the informant perceptions and perspective.

Although number of occurrences of 20 most frequent collocates of the synonyms precise / accurate is different (3438 to 5885) in academic fields of sciences both synonyms have very similar number of occurrences (1770 of precise and 1748 of accurate) (see Figure 3). Both synonyms are also frequent in medicine and philosophy but the number of occurrences differs more than twice.

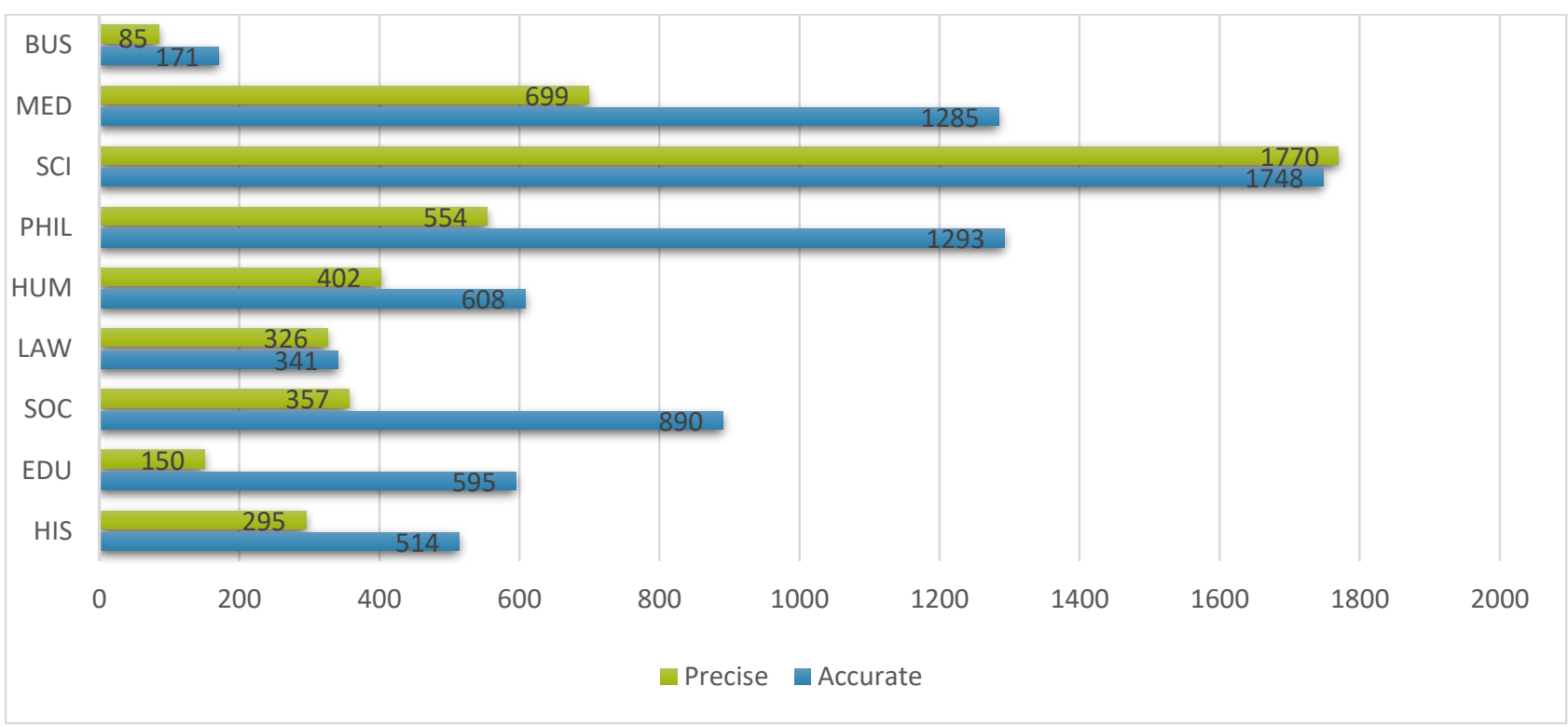

FIGURE 3. Distribution of precise \& accurate across academic fields 
After observing overall profiles of semantic preference and prosody of the three adjective pairs it was noticed that synonyms succinct \& concise have more similarities in their semantic preference than other two pairs of synonyms. Almost a half of the most frequent collocates of the synonyms concise \& succinct coincide and denote a definite or clear expression, review or account of the situation in speech or writing. Differently from the synonym succinct, the synonym concise shows semantic preference for books such as dictionary and encyclopaedia. In the majority of co-occurrence cases, both synonyms have neutral prosody. The frequency of concise in academic register is twice bigger than of the word succinct. Distribution across registers of both synonyms is very similar yielding the highest frequency for both synonyms in humanities. The biggest difference is noticed in law corpora where the word succinct is more frequently used than the word concise while in other academic disciplines the word concise is dominant.

The synonyms coherent \& cohesive demonstrate different semantic preference: only three collocates are the same. The word cohesive tends to co-occur with collective nouns denoting a number of people: group, unit, team, community, society. The synonym coherent usually goes together with the words denoting a plan of actions for particular purpose, a set of ideas or description: policy, strategy, framework, theory, vision, picture. Semantic prosody of both words in predominantly neutral. Only three out of 20 observed most frequent collocates are common for both synonyms. Both synonyms most frequently function in academic fields of history. The word coherent is most common in sciences and history, and the word cohesive is common in history and sociology.

Similar to coherent \& cohesive, the synonyms precise \& accurate exhibit only three overlapping collocates. The word precise demonstrates strong preference to the words related to expression of temporality and locality: moment, date, timing, location, contours. While the word accurate often co-occurs with abstract nouns denoting proving, identification, discovering. The majority of collocates have neutral semantic prosody.

Coherent \& cohesive are the most frequent of the three synonymous pairs in COCA: concise \& succinct correspondingly have 347 and 174 occurrences, coherent \& cohesive correspondingly are found in 1919 and 589 cases, while precise \& accurate have 3438 and 5885 occurrences.

\section{CONCLUSION}

The study showed that near synonyms succinct \& concise, coherent \& cohesive, precise \& accurate have different semantic preference and distribution across registers which should be taken into consideration while building collocations with these words. The analysed synonyms cannot be used interchangeably in all contexts. Although they share similar meaning, their semantic preference in majority of cases is different and they are unevenly scattered across registers. The noun collocates of concise \& succinct often denote a definite or clear expression, review or account of the situation in speech or writing. Only the word concise collocates with the types of books such as dictionary and encyclopaedia. The word cohesive most frequently collocates with collective nouns denoting a number of people, while the synonym coherent usually goes together with the words denoting a plan of actions, a set of ideas or description. The word precise usually goes together with words related to expression of temporality and locality, and the synonym accurate shows preference for abstract nouns denoting 'proving', 'identification', 'discovering'. The words accurate and coherent demonstrated wider range of collocations with adjectives than the rest of the node words. Only the word accurate exhibited adverbs as collocates.

The particular semantic prosody of a node word cannot be accurately identified if its collocates are not analysed in the context. Semantic prosody of succinct \& concise, coherent 
\& cohesive, precise \& accurate contrary to semantic preference and distribution is similar. The research results justify a large percentage of neutral semantic prosody in the academic texts. Prevalence of neutral semantic prosody of all three pairs of adjectives is explained by the fact that they usually collocate with neutral terms. Another explanation of that is that academic register is devoid of strong emotional connotation and mostly present neutralized texts. The cases of positive semantic prosody are related to co-occurrence of two adjectival collocates which reinforce positive semantics. Negative prosody is observed within the collocations of the node words with nouns of negative semantics.

Different distribution of synonymic words across academic fields can be explained by specific character of collocations with the synonyms under the analysis which are common only for texts under a particular topic in a definite academic field. Different distribution across academic disciplines also could be related to the very semantics of synonymic pairs when the synonym having more general meaning is more frequent across all academic disciplines. Future studies could also examine in more specific details how each pair scatters across different academic disciplines.

Awareness of academic vocabulary is considered an obligatory component of academic reading and writing competences which can be directly related to the person's carrier prospects, academic achievements, economic well-being, and social status. The insufficient academic vocabulary knowledge causes difficulties in building academic texts at different levels of education. The findings of the research will help to those who write academic texts to distinguish subtle differences in usage of the synonyms in academic disciplines. It will also encourage researchers to use COCA naturally occurring concordance lines from authentic texts to improve awareness of the English language collocations and create natural flow of language in their academic texts.

It is obvious that the study and usage of synonyms in context has to be based on the corpus. Language users have not only to rely on their prior knowledge of collocations but to get habit of using corpus as a reliable tool against confusing of synonyms in academic contexts. The current study will help to improve the learning, teaching, and research of English academic vocabulary in its many contexts.

\section{REFERENCES}

Banister, Ch. (2016). The academic word list: Exploring teacher practices, attitudes and beliefs through a web-based survey and interviews. The Journal of Teaching English for Specific and Academic Purposes. 4(2), 309-325.

Bi, Z. (2019). A Semantic Prosody Analysis on Two Synonymous Pairs in English Native Speakers' and Chinese Learners' Writings. English Language Teaching, 12(8), 14-19.

Elahi, A. \& Rahbar, M. (2018). Semantic prosody: Its knowledge and appropriate selection of equivalents. International Journal of Foreign Language Teaching \& Research. 6 (22), 73-88.

Esimaje, A. U. (2014). A Descriptive survey of the character of English lexis in sermons. SAGE Open. November-December, 1-16. https://doi.org/10.1177/2158244014563044

Begagić, M. (2013). Semantic preference and semantic prosody of the collocation make sense. Jezikoslovlije. 14(2-3), 403-416.

Coxhead, A. (2011). The Academic Word List 10 years on: research and teaching implications. TESOL Quarterly. 45, 355-362.

Crosson A., McKeown, M., Ward, G. (2019). An Innovative Approach to Assessing Depth of Knowledge of Academic Words. Language Assessment Quarterly. 16(2), 196-216. https://doi.org/10.1080/15434303.2019.1612899 
Gardner, D. \& Davies, M. (2014). A New Academic Vocabulary List. Applied Linguistics. July, 35(3), 305-327, https://doi.org/10.1093/applin/amt015

Green, C. (2019). Enriching the academic wordlist and Secondary Vocabulary Lists with lexicogrammar: Toward a pattern grammar of academic vocabulary. System. 87, 102158. https://doi.org/10.1016/j.system.2019.102158

Hoey, M. (2005). Lexical Priming: A New Theory of Words and Language. London: Routledge. $\mathrm{Hu}, \mathrm{M}$. (2015). A semantic prosody analysis of three adjective synonymous pairs in COCA. Journal of Language and Linguistic Studies. 11(2), 117-131.

Hunston, S. (2007). Semantic prosody revisited. International Journal of Corpus Linguistics. 12, 247-268.

Khani R., Saeedi M., (2017). Material Development and English for Academic Purposes Word Lists; a Reductionist Approach. Journal of English Language Teaching and Learning, 9, 53-72

Lei, L., Liu, D. (2016). A new medical academic word list: A corpus-based study with enhanced methodology. Journal of English for Academic Purposes. 22, 42-53.

Li, E. (2019). A Corpus-assisted Study of Synonyms in EFL Teaching: Take Preserve and Conserve as Example. Linguistics and Literature Studies. 7(2), 39-50. DOI: 10.13189/1ls.2019.070201

Louw, B. (1993). Irony in the text or insincerity in the writer? In: M. Baker, G. Francis, T. Tognini-Bonelli, (Ed.). Text and Technology: In Honour of John Sinclair. Amsterdam: John Benjamins, 157-176.

McDonough, K., Neumann, H., Hubert-Smith, N. (2018) How Accurately do English for Academic Purposes Students use Academic Word List Words? BC TEAL. 3(1), 77-89.

McEnery, T., Hardie, A. (2011). Corpus Linguistics: Method, Theory, and Practice. Cambridge: Cambridge University Press.

Nugroho, D. Y. (2018). A corpus linguistics investigation of two near-synonymous words: rich and wealthy. English education: journal of English teaching and research. 3(2), 118127. https://doi.org/10.29407/jetar.v3i2.12568

Partington, A. (2004). Utterly content in each other's company: semantic prosody and semantic preference. International Journal of Corpus Linguistics. 9(1), 131-156. http://dx.doi.org/10.1075/ijcl.9.1.

Pathan, H., Memon, R., Memon, Sh., Shah, S., Magsi, A. (2018). Academic vocabulary use in doctoral theses: A corpus-based lexical analysis of academic word list (AWL) in major scientific disciplinary groups. International Journal of English Linguistics. 8(4), 282288.

Pecoraria, D., Shaw, Ph. \& Malmström, H. (2019). Developing a new academic vocabulary test. Journal of English for Academic Purposes. 39, 59-71. https://doi.org/10.1016/j.jeap.2019.02.004

Philip, G. (2009). Why prosodies aren't always present: Insights into the idiom principle. In: M. Mahlberg, V. González-Díaz, C. Smith, (Ed.). Proceedings of the Corpus Linguistics Conference CL2009. Liverpool: University of Liverpool.

Philip, G. (2011). Colouring Meaning: Collocation and Connotation in Figurative Language. Amsterdam: John Benjamins Publishing Co.

Sinclair, J. (1991). Corpus, concordance, and collocation. Oxford: Oxford University Press.

Sinclair, J. M. (2003). Reading Concordances. London: Longman.

Sinclair, J. M., Teubert, W. (2004). Interview with John Sinclair conducted by Wolfgang Teubert. In: English Collocation Studies: The OSTI Report. Ed. R. Krishnamurthy. London: Continuum.

Stubbs, M. (2002). Two quantitative methods of studying phraseology in English. International Journal of Corpus Linguistics. 7(2), 215-244. 
Wang, Q. (2019). A Corpus-based contrastive study on semantic prosody of English near synonyms: A case study of Motive and Motivation. Journal of Arts and Humanities. 8(1), 2019, 1-15.

Wang, H. \& Zou, Y. (2019). A Corpus-Based Study of Semantic Collocations of the Verb "Feel" in English Public Speaking Setting: Chinese EFL V.S Native Speakers. International Journal of English Linguistics. 9 (1), 251-260.

Xue, G. \& Nation, I.S.P. (1984). A university word list. Language Learning and Communication. 3, 215-229.

Zhang, C. (2010). An overview of corpus-based studies of semantic prosody. Asian Social Science. 6(6), 190-194.

\section{SOURCES}

https://www.english-corpora.org/coca/ www.wordandphrase.info/academic Oxford Advanced Learner's Dictionary. $9^{\text {th }}$ edition. (2015). Oxford University Press.

\section{ABOUT THE AUTHOR}

Prof. Dr. Linas Selmistraitis's scientific interests are semantics, lexicology, and morphology. He publishes articles in Lithuanian, English and Russian. Prof. Dr. Linas Selmistraitis has developed his professional qualification and delivered lectures in universities in Belarus, China, Czech Republic, Finland, Germany, Great Britain, Hungary, India, Kazakhstan, Poland, Russia, Slovenia, Spain, and Turkey. He was a member of $7 \mathrm{PhD}$ defence committees. 